\title{
Burden of Acute Respiratory Tract Infections as Seen in University of Port Harcourt Teaching Hospital Nigeria
}

\author{
Lucy Eberechukwu Yaguo Ide and Tochi Ada Uchenwa-Onyenegecha \\ Department of Paediatrics and Child Health, University of Port Harcourt Teaching Hospital, Port Harcourt, Rivers State +234, \\ Nigeria
}

\begin{abstract}
Acute respiratory infections (ARI) particularly lower respiratory tract infections (LRTI) are the leading cause of death among children under five years of age. ARI is estimated to account for approximately 4 million deaths annually with more than two third of these deaths occurring in Africa. Despite its importance in regard to morbidity as well as childhood mortality, the epidemiology particularly in Africa and Port Harcourt, remains understudied, hence the need for this study. This study therefore aims to describe the burden of acute respiratory infections as seen at the University of Port Harcourt Teaching Hospital. This was a retrospective review of all cases of ARI seen at the ARI clinic of the department of Paediatrics, University of Port Harcourt Teaching Hospital from January 2010 to November 2011. Information on demographic data, diagnosis, month and year of presentation at the ARI clinic was retrieved from the nurse's clinic records and analysed using Statistical package for Social Sciences version 15. Descriptive statistics was used and presented in simple frequencies and in tables. There were a total of 3477 cases of ARI seen at the ARI clinic during this period, 1910 (54.9\%) males and 1523 (43.8\%) female. M: F ratio was 1.3:1. The highest incidence of ARI was in the month of July 373 (10.7\%), which is the peak of the rainy season. The commonest ARI seen was cough and catarrh no pneumonia accounting for 2342 cases $(67.4 \%)$, followed by tonsillitis $829(23.8 \%)$ and pneumonia $229(6.6 \%)$. Malaria was the most common associated condition 128 $(3.7 \%)$. Over $90 \%$ of them were under-fives, with $60 \%$ of these being infants. Acute respiratory infections still contribute to under-five and infant morbidity in our environment.
\end{abstract}

Key words: Burden, acute respiratory tract infection.

\section{Introduction}

Acute Respiratory Infections (ARI) has remained a major cause of morbidity and mortality globally [1-3]. ARI accounts for approximately 4 to 5 million deaths annually [1-5]. In 2010, 5.8 million deaths were due to ARI [6]. ARI are the most common reason that most people access health services around the world accounting for $20 \%-40 \%$ of all hospitalisations among children and are responsible for at least $6 \%$ of the world's disability and death [4]. ARI are the third largest cause of mortality in the world and the top killer in low- and middle-income countries [4, 5, 7]. The mortality due to ARI is ten to fifty times higher in developing countries than developed countries [8]. More than two third of the global burden from ARI

Corresponding author: Lucy Eberechukwu Yaguo Ide, senior lecturer, research field: community paediatrics. related deaths occur in Africa [7]. The burden of ARI in most developing countries including Nigeria is largely unknown, however, on an average, it has been reported that every child has about 5 to 6 episodes of ARI in a year accounting for about $30 \%-50 \%$ of the total paediatric outpatient visits $[9,10]$. Data from national demographic health survey 2013 reported the prevalence of ARI in Nigeria to be about 2\% [11].

ARIs are a group of heterogeneous diseases caused by a diverse group of organisms in which the anatomical site(s) involved consists of the airways from the nostrils, pharynx down to the alveoli $[12,13]$. ARIs may be classified as upper respiratory tract infections (URTIs) or lower respiratory tract infections (LRTIs) [12, 13]. The upper respiratory tract consists of the airways from the nostrils to the vocal cords in the larynx, including the paranasal sinuses and the middle ear $[12,13]$. The lower respiratory tract covers the 


\section{Burden of Acute Respiratory Tract Infections as Seen in University of}

Port Harcourt Teaching Hospital Nigeria

continuation of the airways from the trachea and bronchi to the bronchioles and the alveoli $[12,13]$. URTIs in children include rhinitis (common cold), tonsillitis, sinusitis, otitis media, epiglottitis, etc. [12, 13]. The common LRTIs in children are pneumonia and bronchiolitis, which are the major reasons for hospital admissions and mortality among children presenting with ARI [12]. Pneumonia accounts for about 2 million deaths among children under 5 years of age annually [14]. The aetiology of ARI is diverse, and most URTIs are of viral aetiology. Studies have shown that bacterial causes account for up to $70 \%$ of childhood pneumonia; mainly, Streptococcus pneumoniae followed by Haemophilus influenzae type $b$ (Hib), Staphylococcus aureus and Klebsiella pneumoniae, respectively while viral aetiology studies show that respiratory syncytial virus is the leading viral cause of pneumonia, followed by influenza $\mathrm{A}$ and $\mathrm{B}$, parainfluenza, human metapneumovirus, and adenovirus, respectively $[12,14$, 15]. The diversity of microorganisms implicated in ARIs makes the formulation of universal treatment difficult.

The risk factors for ARIs have been highlighted in various studies to be diverse due to differences in living conditions and other environmental factors [14, 16-19]. Studies in developing countries have reported that nutritional factors ,overcrowding, parental smoking were associated with ARI $[17,18]$ while in developed countries gender, maternal education, exposure to childcare, preschool, family income and private health insurance have been reported to have an association with ARI amongst children [16, 19].

ARI most commonly presents with symptoms such as cough, nasal discharge, and fever, while the most common signs referable to the respiratory tract are abnormal breathing sounds, tachypnea, and chest retraction [2]. These symptoms and signs have been used by WHO to develop the ARI case management for primary health care providers which we have used in our ARI clinic over the years and found it very useful.
The epidemiology of ARI in this Unit is not known hence the need for this study to know the burden of ARI and to plan meaningful interventions to enable us contribute towards achieving MDG4 (millennium development goal 4).

\section{Materials and Methods}

This was a retrospective study of all cases of ARI seen at the ARI clinic of the Department of Paediatrics, University of Port Harcourt teaching hospital from January 2010 to November 2011.

\subsection{Subjects and Data Collection}

The ARI clinic caters for children two months to sixty months who have signs and symptoms of ARI. Information on demographic data, diagnosis, month and year of presentation at the ARI clinic was retrieved from nurses' clinic records.

\subsection{Case Definition}

This was according to World Health Organization working group on case management of ARIs, which defined ARI as a clinical state presenting with rapid breathing more than expected upper limit for age with or without chest in drawing, too sick to feed, nasal discharge, cough, fever with or without auscultatory findings of less than 2 weeks [20]. Acute upper respiratory tract infections were grouped as syndromes involving the upper airways such as nasopharyngitis, sinusitis, otitis media, epiglottis and tonsillitis. Lower respiratory tract infections involved infection of the airways from the trachea and bronchi to the bronchioles and the alveoli. Pneumonia was defined as a case, which had fast breathing more than expected for age, breathing difficulty, cough, fever, chest in-drawing with or without auscultatory findings such as inspiratory and expiratory crackles, rhonchi or bronchial breath sounds of less than or equal to 2 weeks duration. Bronchiolitis was defined as a case, which had respiratory distress, low grade fever and expiratory wheeze [12]. 


\subsection{Statistical Analysis}

Data was analysed using statistical package for social sciences version 15. Descriptive statistics was used and presented in simple frequencies and percentages.

\section{Results}

There were a total of 3477 cases of ARI seen at the ARI clinic during this period, 1910 (54.9\%) males and $1523(43.8 \%)$ female, the sex for $44(1.3 \%)$ patients was missing giving a male to female ratio of 1.3:1. Table 1 shows the sex distribution of ARI cases seen.

ARI was most frequent in the peak of the rainy season, with 373 (10.7\%) cases seen in the month of July. Fig. 1 shows the monthly distribution of ARI case seen within the study period.

The commonest ARI seen was cough and catarrh no pneumonia accounting for 2342 cases $(68.3 \%)$ followed by tonsillitis 829 (23.8\%), pneumonia 229 (6.6\%), bronchiolitis $34(1 \%)$ and the least acute otitis media $9(0.26 \%)$. Malaria was the most common associated condition 128 (3.7\%), other associated conditions included sepsis, acute watery diarrhoea, measles and pertussis. Over $90 \%$ of them were under-fives with about $60 \%$ of these being infants. The data on the age for 132 (3.8\%) children was missing, 1988 (57.2\%) were below 12 months of age, 1256 (36.1\%) were between 12 to $<60$ months and 101 (2.9\%) were above 60 months.

\section{Discussion}

ARIs have remained a major contributor to morbidity among children. In our study, a total of 3477 cases of ARIs were seen over a 23 month study period which highlights the high burden of ARIs in our locale. Most cases of ARIs seen in our study were upper respiratory tract infections which is consistent with the reports by other authors [9]. The cases of pneumonia seen in our review was comparable to the findings by Acharya et al. [9] and Zaman et al. [10] in South India

Table 1 Sex distribution of ARI cases seen.

\begin{tabular}{lll}
\hline Sex & Total & Percentage (\%) \\
\hline F & 1523 & 43.8 \\
M & 1910 & 54.9 \\
Unidentified & 44 & 1.3 \\
\hline
\end{tabular}

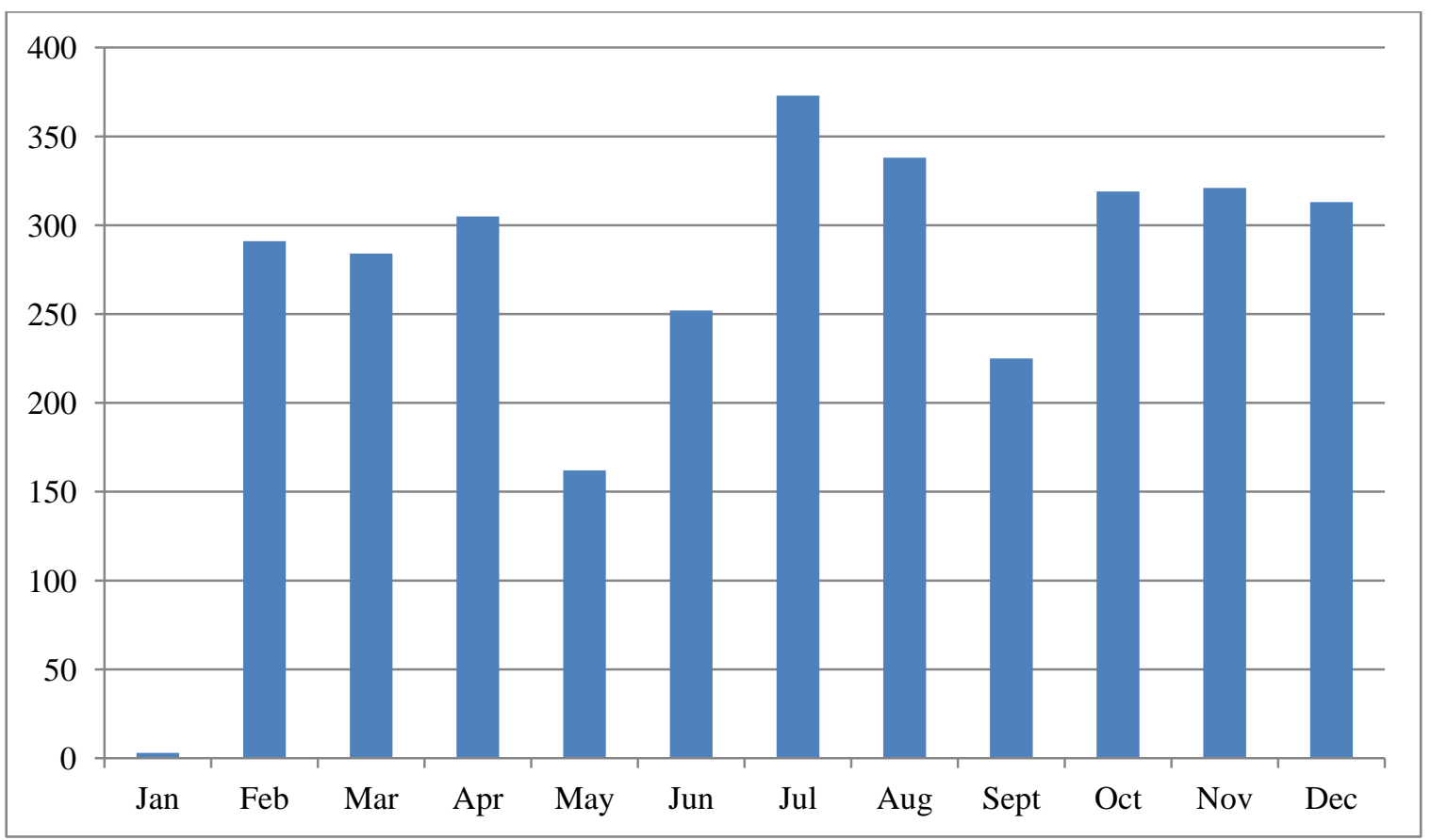

Fig. 1 Monthly distribution of ARI cases seen. 
and Bangladesh but lower than that reported in the study by Ujunwa and Ezeonu [18] in Enugu. This difference may the due to the differences in the methodology. Our study was a retrospective review of all ARI cases seen at the ARI clinic of the UPTH (University of Port Harcourt Teaching Hospital) and therefore some cases of pneumonia seen at the emergency ward were not included while the study by Ujunwa and Ezeonu [18] was a prospective study carried out in 3 hospitals in Enugu metropolis and only children less than 5 years were recruited in their study. In our study, most of the children presenting with ARI were under five years of age with most of them being infants which is similar to the findings by other authors $[16,18,21]$. This may be attributed to the fact that younger children are less immune competent compared to the older children and are therefore more likely to get infected. ARI was commoner in males than females in our study which is similar to the reports by Oyedeji and Osinusi [2], Ujunwa and Ezeonu [18] and Yilgwan et al. [21]. However, Chen et al. [16] observed that ARI was commoner in females. On the other hand, Acharya et al. [9] observed no sex difference in their study. There was seasonal variation in the cases of ARI seen in our study with most cases seen at the peak of the rainy season. This is consistent with the report by Fagbule et al. [22] and Zaman et al. [10]. The higher number of cases seen during this season may be due to the reduction in atmospheric temperature during the rainy season. On the other hand, Koch et al. [23] in their study observed no clear seasonal variation. The reason for differences in the seasonal trends reported by various authors may be attributed to varying climate and therefore temperature differences at different times in different regions. The commonest associated condition in our study was malaria which is similar to the finding by Ujunwa and Ezeonu [18].

\section{Conclusion}

Acute respiratory infections still contribute to under-five and infant morbidity in our environment.

\section{References}

[1] Mulholland, K. 2003. "Global Burden of Acute Respiratory Infections in Children: Implications for Interventions.” Pediatr. Pulmonol. 36 (6): 469-74.

[2] Oyejide, C. O., and Osinusi, K. 1990. “Acute Respiratory Tract Infection in Children in Idikan Community, Ibadan, Nigeria: Severity, Risk Factors and Frequency of Occurrence." Rev. Infect. Dis. 12 (8): 1042-6.

[3] Rudan, I., Tomaskovic, L., Boschi-Pinto, C., and Campbell, H. 2004. "Global Estimate of the Incidence of Clinical Pneumonia among Children under Five Years of Age.” Bull World Health Organ. 82 (12): 895-903.

[4] Williams, B. G., Gouws, E., Boschi-Pinto, C., Bryce, J., and Dye, C. 2002. "Estimates of World-wide Distribution of Child Deaths from Acute Respiratory Infections." Lancet Infect. Dis. 2 (1): 25-32.

[5] Leowski, J. 1986. "Mortality from Acute Respiratory Infections in Children under 5 Years of Age: Global Estimates." World Health Stat. Q. 39 (2): 138-44.

[6] Rafael, L., Mohsen, N., and Kyle, F. 2012. "Global and Regional Mortality from 235 Causes of Death for 20 Age Groups in 1990 and 2010: A Systematic Analysis for the Global Burden of Disease Study." Lancet 380 (9859): 2095-128.

[7] World Lung Foundation. 2010. Four Million Deaths Each Year caused by Acute Respiratory Infections-New Atlas Details Pandemic. Assessed September 4, 2015. www.worldlungfoundation.org/ht/display/ReleaseDetails/ i/12503/pid/6858

[8] Chatterjee, S. 2006. "A Study of Epidemiological Factors Related to Acute Respiratory Infection in under Five Children Attending the Immunization Clinic of Calcutta National Medical College and Hospital." The Internet Journal of Pulmonary Medicine 7 (2): 1-6.

[9] Acharya, D., Prasanna, K. S., Nair, S., and Rao, R. S. 2003. "Acute Respiratory Infections in Children: A Community Based Longitudinal Study in South India." Indian J. Public Health 47 (1): 1-13.

[10] Zaman, K., Baqui, A. H., Yunus, M., Sack, R. B., Bateman, O. M., Chowdhury, H. R., and Black, R. E. 1997. “Acute Respiratory Infections in Children: A Community Based Longitudinal Study in Rural Bangladesh.” J. Trop. Pediatr. 43 (3): 133-7.

[11] National Population Commission (NPC) (Nigeria) and ICF International. 2014. Nigeria Demographic and Health Survey 2013. Abuja, Nigeria, and Rockville, Maryland, USA: NPC and ICF International.

[12] Johnson A-W, B. R. 2007. "Acute Respiratory Infections." In Paediatrics and Child Health in Tropical Region, edited by Azubuike, J. C., and Nkanginieme, K. E. O., 2nd ed. Owerri African Educational Services. 396-425. 
[13] Simeos, E. A. F., Cherian, T., Chow, J., Shahid-Salles, S. A., Laxminarayan, R., and John, T. J. 2006. "Acute Respiratory Infections in Children." Disease Control Priorities in Developing Countries. Assessed September 4, 2015. www.ncbi.nlm.nih.gov.books/NBK11786

[14] Rudan, I., Boschi-pinto, C., Biloglav, Z., Mulholland, K., and Campbell, H. 2008. "Epidemilogy and Etiology of Childhood Pneumonia.” Bull World Health Organ 86 (5): 408-16.

[15] Johnson, A. W., Osinusi, K., Aderele, W. I., Gbadero, D. A., Olaleye, O. D., and Adeyemi-Doro, F. A. 2008. "Etiologic Agents and Outcome Determinants of Community Acquired Pneumonia in Urban Children: A Hospital-based Study." J. Natl. Med. Assoc. 100 (4): 370-85.

[16] Chen, Y., Williams, E., and Kirk, M. 2014. "Risk Factors for Acute Respiratory Infection in the Australian Community." PLoS ONE 9 (7): e101440.

[17] Mathew, J. L., Patwari, A. K., Gupta, P., Shah, D., Gera, T., Gogia, S., Mohan, P., Panda, R., and Menon, S. 2011. "Acute Respiratory Infection and Pneumonia in India: A Systematic Review of Literature for Advocacy and Action: UNICEF-PHFI Series on Newborn and Child Health, India." Indian Pediatr. 48 (3): 191-218.

[18] Ujunwa, F. A., and Ezeonu, C. T. 2014. "Risk Factors for
Acute Respiratory Tract Infections in under Five Children in Enugu South East Nigeria." Ann. Med. Health Sci. Res. 4 (1): 95-9.

[19] Koch, A., Molbak, K., Homoe, P., Sorensen, P., Hjuler T, Ehmer, M., June, P., Freddy, K. P., Ove Rosing, O., and Mads, M. 2003. "Risk Factors for Acute Respiratory Tract Infections in Young Greenlandic Children." Am. J. Epidemiol. 158 (4): 374-84.

[20] Lanata, C. F., Rudan, I., Boschi-Pinto, C., Tomaskovic, L., Cherian, T.,Weber, M., and Campbell, H. 2004. "Methodological and Quality Issues in Epidemiological Studies of Acute Lower Respiratory Infections in Children in Developing Countries." Int. J. Epidemiol. 33 (6): 1362-72.

[21] Yilgwan, C. S., John, C., Abok, I. I., and Okolo, S. N. 2013. "Pattern of Acute Respiratory Infections in Hospitalized Children under Five years of Age in Jos Nigeria." Niger. J. Pead. 40 (2): 150-3.

[22] Fagbule, D., Parakoyi, D. B., and Spiegel, R. 1994. "Acute Respiratory Infections in Nigerian Children: Prospective Cohort Study of Incidence and Case Management." $J$. Trop. Pediatr. 40 (5): 279-84.

[23] Koch, P., Sorensen, P., and Homoe, P. 2002. "Population Based Study of Acute Respiratory Infections in Children, Greenland." Emerg. Infect. Dis. 8 (6): 586-93. 